\title{
Antibiotics Susceptibility Profile of Listeria Species Isolated from Poultry Wastes and Fishpond Water from Private and Institutional Farms in Ibadan, Nigeria
}

\author{
Olutayo Israel Falodun ${ }^{{ }^{\star}}$ and Moturayo Janet Amusan ${ }^{1}$ \\ ${ }^{1}$ Department of Microbiology, University of Ibadan, Ibadan, Nigeria.
}

Authors' contributions

This work was carried out in collaboration between both authors. Author OIF designed the study and the protocol. Authors OIF and MJA managed literature search, data acquisition and wrote the draft. Both authors read and approved the final manuscript.

Article Information

DOI: $10.9734 / \mathrm{JABB} / 2017 / 34566$

Editor(s):

(1) Cosmas Nathanailides, Dept Fisheries and Aquaculture Technology, Technological Educational Institute of West Greece,

\section{ABSTRACT}

Introduction: Untreated waste being discharged into the environment due to proliferation of poultry and fish farms can constitute a public health threat to human. Listeria, an emerging pathogen is commonly associated with food. This study aimed at determining the antibiotic resistant pattern of Listeria species isolated from poultry droppings and fish pond water in Ibadan.

Materials and Methods: Poultry waste and fishpond water samples were collected between April and July, 2016. Listeria Selective Agar was used to isolate Listeria species and identified using conventional methods. Antimicrobial susceptibility testing was done using the Kirby-Bauer disk diffusion method against ampicillin, cloxacillin, amoxicillin, streptomycin, ceftriazone, chloramphenicol, ciprofloxacin, ofloxacin, sulfamethoxazole-trimethoprim and tetracycline.

Results: A total of forty samples were collected and 105 Listeria spp. isolated; $62.9 \%$ from poultry waste and $37.1 \%$ from fishpond water. From the institutional fish pond and poultry waste, $18.1 \%$ and $51.4 \%$ isolates were obtained while from private fish pond and poultry waste, $19.1 \%$ and $11.4 \%$ isolates respectively were obtained. The isolates were Listeria monocytogenes (27.6\%), L. innocua 
(8.6\%), L. ivanovii (16.2\%) and other Listeria spp. (47.6\%). All the isolates were resistant to ampicillin and ciprofloxacin; all $L$. monocytogenes, $L$. innocua and $L$. ivanovii were resistant to ceftriaxone, but $89.3 \%$ of the other Listeria spp. showed resistance. Furthermore, all (100\%) the isolates obtained from private poultry farm were resistant to chloramphenicol while $53.3 \%$ were resistant to trimethoprim/sulfamethoxazole. Also, $12.2 \%$ of the isolates were found to be resistant to a combination of six antibiotics including: Ampicillin, amoxicillin, ceftriaxone, streptomycin and trimethoprim/sulfamethoxazole.

Conclusion: This study revealed that poultry waste and fish pond water from the selected farms could be a potential source for the transmission of multi-drug resistant bacteria to humans. Proper treatment of poultry waste and fish pond water should be ensured before discharge into the environment.

Keywords: Listeria species; antibiotics resistance; fish pond water, poultry waste.

\section{INTRODUCTION}

Listeria species are members of the family Listeriaceae, with eleven species of Listeria within the phylogeny and include $L$. monocytogenes, L. ivanovii, L. grayi, L. innocua, L. welshmeri, L. seeligeri, L. marthii, L. maris, $L$. rocourtiae, $L$. fleischmannii and $L$. weihenstephanensis [1]. Some Listeria spp. are pathogenic causing opportunistic infections in both human and animals leading to Listeriosis; among these, Listeria ivanovii and $L$. monocytogenes cause infections in animal and human [2]. Listeriosis is an emerging infectious disease of major public health concern worldwide because it is associated with foodborne outbreak with significant risk of morbidity and mortality [3]. The main route of entry of this pathogen is the intestinal mucosa of the host after ingestion. The clinical manifestations of listeriosis depends on the host and may be either invasive, when L. monocytogenes penetrates the blood-brain-barrier causing severe infections of the brain or non invasive, when the placental is penetrated leading to infection of the foetus. Invasive form of listeriosis affects high-risk people, including immunocompromised individuals, neonatal, and elderly persons usually present with septicemia or meningitis [4]. While non-invasive listeriosis, also referred to as febrile listerial gastroenteritis is a milder form of infection; It manifests symptoms such as diarrhea, fever, headache and muscle pain [5].

The most important aspect of this organism in food hygiene is the ability of the bacteria to survive in a wide range of temperatures and biofilms formation on various environmental surfaces, which serve as natural habitats or reservoirs [6]. The raising of food animals with antibiotics either as growth promoters of for infection control results in harboring significant populations of antibiotic-resistant bacteria, which can be transmitted to humans through direct contact with the animals or through their products such as meat, eggs, and milk [7]. Aquatic ecosystems such as fish ponds and rivers have been recognized as a reservoir of antibiotic resistant bacteria and antibiotic resistance genes [8]. An outbreak of listeriosis was reported in a herd of cattle [9] from the south-western city of Ibadan while in a recent study conducted also in lbadan on abattoir wastewater, Listeria spp. isolated from the wastewater include $L$. monocytogenes (26.8\%), L. innocua (20.7\%), L. ivanovii (18.3\%) and other Listeria species $(34.2 \%)$ [10].

A number of studies have reported isolation of Listeria species in Nigeria and elsewhere from food animals and their products such as pork, cattle and fish [11,12] as well as from environmental samples including municipal water, and abattoir wastewater $[10,13]$. However, there is a dearth of information from poultry waste and fish pond water especially in Nigeria. There are reports of resistance of Listeria spp. to antibiotics such as chloramphenicol and ampicillin [14]. In a study conducted on human samples and slaughterhouse, it was observed that Listeria species exhibited a high level of resistance to antibiotics such as clindamycin, daptomycin, fluoroquinolone as well as to the third and fourth generation antibiotics cephalosporins [15]. Also in a recent study carried out in Ibadan on samples collected from abattoir slaughter slab and drainage, all the Listeria spp. were found to be resistant to ampicillin together with a high resistant rate to ceftriazone, amoxicillin/clavulanate and tetracycline [10]. This present study was therefore carried out to determine the occurrence and antibiotic resistant pattern of Listeria species isolated from poultry droppings and fish pond 
water from private and tertiary farms in Ibadan metropolis.

\section{MATERIALS AND METHODS}

\subsection{Study Area}

The study sites were private poultry farm in Moniya, private fish farm in Ojoo and University of Ibadan poultry farm and fish pond. Ibadan is located in South-western part of Nigeria, it was founded in 1829; it is the largest city in West Africa. Ibadan is located at $7024^{\prime} \mathrm{N}$; $3054^{\prime} \mathrm{E}$; 234 $\mathrm{m}$ above sea level [16].

\subsection{Sample Collection}

Samples of poultry waste and fish pond water were aseptically collected into sterile sampling bottles. Samples were transported immediately to the laboratory in ice packs for microbiological analyses. Samples were collected weekly over a period of ten weeks between April and July, 2016.

\subsection{Isolation and Identification of Listeria Species}

Isolation of Listeria species was carried out according to the method of Akano et al. [17]. Analysis of the poultry wastes and fish pond water was carried out using the Listeria Selective Agar Base (Oxoid). The media was prepared according to manufacturers' instruction and supplemented with a vial of Listeria Selective Supplement. The poultry wastes and fish pond water were serially diluted and the standard pour plate technique was used by plating out $1 \mathrm{ml}$ of the appropriate dilutions on the listeria selective agar. The cultured plates were incubated at $35^{\circ} \mathrm{C}$ for 24-48 hours. Colonies with gray colour and dark background, were sub-cultured on Listeria Selective Agar media to obtain pure isolates and the isolates were identified using standard biochemical tests.

\subsection{Antibiotics Susceptibility Test of the Isolates}

Using the standard disk diffusion technique on Mueller-Hinton agar, antibiotics susceptibility test of the isolates was carried out based on the recommendation of Clinical Laboratory Standards Institute [18]. A total of ten antibiotics obtained from Oxoid, U.K. were used which include: tetracycline $(30 \mu \mathrm{g})$, streptomycin (10 $\mu \mathrm{g})$, cloxacillin $(5 \mu \mathrm{g})$, ofloxacin $(5 \mu \mathrm{g})$, amoxillin $(5 \mu \mathrm{g})$, ceftriaxone $(30 \mu \mathrm{g})$, sulfamethoxazoletrimethroprim $(25 \mu \mathrm{g})$, chloramphenicol $(30 \mu \mathrm{g})$, ampicillin $(10 \mu \mathrm{g})$ and ciprofloxacin $(5 \mu \mathrm{g})$. The isolates were sub cultured and colonies of 18-24 hour old culture was picked and suspended in a tube containing sterile normal saline with turbidity adjusted to $0.5 \mathrm{McF}$ arland standards. The suspension was uniformly spread over already prepared solidified Mueller Hinton agar plates using a sterile swab stick. Sterile forceps was used to aseptically place the antibiotics disc on the inoculated plates and incubated at $37^{\circ} \mathrm{C}$ for 18-24 hours. After the incubation period, the zones of inhibition were measured, recorded and interpreted using the CLSI standards.

\section{RESULTS}

A total of 105 Listeria spp. were isolated from poultry waste and fishpond water samples comprising of 66 (62.9\%) and 39 (37.1\%) isolates from poultry waste and fishpond water samples respectively. The occurrence of the isolates showed that $29(27.6 \%)$ were Listeria monocytogenes; 17 (16.2\%) were L. ivanovii, 9 $(8.6 \%)$ were L. innocua while 50 (47.6\%) belongs to other Listeria species (Table 1).

The antibiotic susceptibility test results revealed that all $(100 \%)$ the Listeria isolates were resistant to ampicillin and ciprofloxacin. Likewise, all $(100 \%)$ the L. ivanovii were resistant to cloxacillin and similarly, all $(100 \%)$ the $L$. ivanovii, $L$. innocua and $L$. monocytogenes were resistant to ceftriaxone. Furthermore, the results of the susceptibility test showed that resistant to ceftriaxone, cloxacillin and sulfamethoxazoletrimethoprim were $97.1 \%, 83.8 \%$ and $53.3 \%$ respectively while it was observed that among the isolates that showed resistant to sulfamethoxazole-trimethoprim, the highest was among the $L$. ivanovii (58.8\%) followed by L. monocytogenes $(58.6 \%)$, the other Listeria spp. (50.0\%) and L. innocua (44.4\%). However, a low resistant rate was observed among the isolates to tetracycline $(29.5 \%)$, chloramphenicol $(15.2 \%)$ and streptomycin (32.4\%). Moreover, none of the $L$. ivanovii, $L$. innocua and $L$. monocytogenes showed any resistance to ofloxacin (Table 2).

In addition, all (100\%) the isolates obtained from the fish pond water exhibited resistant to ceftriaxone while it was $94.4 \%$ resistance for isolates from the poultry waste. While the Listeria spp. isolated from the poultry waste showed 
$1.5 \%, 22.7 \%$ and $39.4 \%$ resistance to ofloxacin, chloramphenicol and tetracycline respectively, none of the isolates obtained from the fish pond water samples showed any resistant to the antibiotics. However, all (100\%) the isolates obtained from the institution fish pond water samples were resistant to sulfamethoxazoletrimethoprim while those isolated from the private fishpond water showed resistance of $50 \%$ to the antibiotic. Similarly, the rate of resistance of the Listeria isolates from the private poultry farm to tetracycline $\quad(100 \%), \quad$ sulfamethoxazoletrimethoprim (100\%) and chloramphenicol $(91.7 \%)$ were high while the ones isolated from the institutional fishpond showed a lower resistance of $25.9 \%, 29.6 \%$ and $7.4 \%$ to the antibiotics respectively (Table 3 ).

The result of the phenotypes of resistance of the isolates to antibiotics from the fish pond water and the poultry waste is as shown in Table 4 and Table 5 respectively. The result showed that from fishpond water, all $(100 \%)$ the isolates were resistant to the combination of three antibiotics that included ampicillin, ceftriaxone and ciprofloxacin while $74.4 \%$ of the isolates were resistant to another set of three drugs which include: sulfamethoxazole-trimethoprim, ceftriaxone and ciprofloxacin. It was also observed that $41.0 \%$ of the isolates were resistant to the following four drugs: streptomycin, sulfamethoxazole-trimethoprim, ceftriaxone and ciprofloxacin while $35.9 \%$ of the isolates were resistant to the combination of another set of four drugs including amoxillin, sulfamethoxazole-trimethoprim, ceftriaxone and ciprofloxacin. Furthermore, among the isolates obtained from the poultry wastes, $72.7 \%$ were resistant to the combination of ampicillin, ceftriaxone and ciprofloxacin while it was observed that $10.5 \%$ were resistant to a combination of six antibiotics including ampicillin, streptomycin, sulfamethoxazole-trimethoprim, chloramphenicol, ciprofloaxin and tetracycline while $1.5 \%$ of the isolates were resistant to a combination of another set of six antibiotics including ampicillin, tetracycline, amoxicillin, ciprofloaxin, sulfamethoxazole-trimethoprim and chloramphenicol (Table 5).

\section{DISCUSSION}

In Nigeria, little is known about the true state of listeriosis especially in relation to the environment because there have not been comprehensive studies carried out on Listeria in the country. Although, listeriosis is an important disease of public health and animals coupled with the possibility of the environment being a route of transmission, there has been little or no attention given to it. Isolation of $L$. monocytogenes and $L$. ivanovii from both the fish pond water and the poultry waste studied is an indication that the possibility of these environmental samples serving as route of transmission of the pathogens to both human and animals cannot be ruled out because these Listeria species has been reported to be responsible for illness in human and animals. While $L$. monocytogenes is principally a pathogen of human and animals, L. ivanovii is a pathogen of animals as well as being implicated in human infection occasionally [2]. Different species of Listeria were isolated from the environmental samples studied which corroborates previous reports in which Listeria species were isolated from environmental samples including abattoir wastewater, butchers tables, fresh water samples and municipal waste effluents $[1,10,15,19]$. It was observed from this study that the occurrence of the isolates was $27.6 \%$ (L. monocytogenes), $16.2 \%$ (L. ivanovii) and $8.6 \%$ (L. innocua); This is similar to the rate of occurrence of the isolates in a recent study conducted on abattoir wastewater in which $L$. monocytogenes had the highest rate of occurrence compared to the other species [10]. However, from the fish pond, the occurrence of the isolates as observed in this study was lower compared to same isolates from the poultry droppings. The reason for this may be as a result of the direct introduction of antibiotics into the fish pond water which might have possibly eliminated the susceptible strains thereby reducing the microbial load.

The resistance of the isolates obtained in this study to ampicillin (100\%) is comparable to the (total resistance) reported from previous studies which was carried out on homemade white cheese and fishes respectively [20,21]. In a study carried out in South Africa [13], resistance of Listeria to ciprofloxacin $(91 \%)$ was high but a bit lower compared to the $100 \%$ observed in this study, the little disparity may be due to the studied samples. The South African study was on municipal wastewater. However, this observation is not in agreement with $0 \%$ ciprofloxacin resistance reported from a study on ready to eat foods in South Africa as well as another study from Mangalore, India on clinical and food samples [22,23]. Generally, resistance of the isolates in this study to chloramphenicol (15.2\%), tetracycline (29.5\%) 
and ofloxacin $(0.9 \%)$ was lower compared to the resistance reported on abattoir wastewater to the same set of antibiotics which were $41.5 \%, 65.5 \%$ and $6.1 \%$ for chloramphenicol, tetracycline and ofloxacin respectively [10]. However, the latter study was on abattoir wastewater as against the poultry waste and fish pond water in this study.

\section{Table 1. Number and percentage of occurrence of Listeria spp. isolated from the} environmental samples $n(\%)$

\begin{tabular}{llllll}
\hline Source & $\begin{array}{l}\text { Listeria } \\
\text { monocytogenes }\end{array}$ & $\begin{array}{l}\text { Listeria } \\
\text { ivanovii }\end{array}$ & $\begin{array}{l}\text { Listeria } \\
\text { innocua }\end{array}$ & $\begin{array}{l}\text { Listeria } \\
\text { spp. }\end{array}$ & Total \\
\hline $\begin{array}{l}\text { Poultry waste } \\
\text { (Institution) }\end{array}$ & $12(11.4)$ & $12(11.4)$ & $2(1.9)$ & $28(26.7)$ & $54(51.4)$ \\
$\begin{array}{l}\text { Poultry waste (Private) } \\
\begin{array}{l}\text { Fish pond water } \\
\text { (Institution) }\end{array}\end{array}$ & $7(6.7)$ & $1(1.0)$ & $0(0.0)$ & $4(3.8)$ & $12(11.4)$ \\
$\begin{array}{l}\text { Fish pond water } \\
\text { (Private) }\end{array}$ & $6(5.7)$ & $2(1.9)$ & $3(2.9)$ & $8(7.6)$ & $19(18.1)$ \\
Total & $4(3.8)$ & $2(1.9)$ & $4(3.8)$ & $10(9.5)$ & $20(19.1)$ \\
\hline
\end{tabular}

Table 2. Antibiotic resistance patterns of all the Listeria spp. isolated from the environmental samples $\mathrm{n}(\%)$

\begin{tabular}{llllll}
\hline Antibiotics & $\begin{array}{l}\text { L. monocytogenes } \\
\mathbf{N}=\mathbf{2 9}\end{array}$ & $\begin{array}{l}\text { L. ivanovii } \\
\mathbf{N}=\mathbf{1 7}\end{array}$ & $\begin{array}{l}\text { L. innocua } \\
\mathbf{N}=\mathbf{9}\end{array}$ & $\begin{array}{l}\text { Listeria spp. } \\
\mathbf{N}=\mathbf{5 0}\end{array}$ & $\begin{array}{l}\text { Total } \\
\mathbf{N}=\mathbf{1 0 5}\end{array}$ \\
\hline Ampicillin $(10 \mu \mathrm{g})$ & $29(100.0)$ & $17(100.0)$ & $9(100.0)$ & $50(100.0)$ & $105(100.0)$ \\
Streptomycin $(10 \mu \mathrm{g})$ & $11(37.8)$ & $5(29.4)$ & $1(11.1)$ & $17(34)$ & $34(32.4)$ \\
Ceftriazone $(30 \mu \mathrm{g})$ & $29(100.0)$ & $17(100.0)$ & $9(100.0)$ & $47(94.0)$ & $102(97.1)$ \\
Chloramphenicol $(30 \mu \mathrm{g})$ & $7(24.1)$ & $2(11.7)$ & $0(0.0)$ & $7(14.0)$ & $16(15.2)$ \\
Sulfamethoxazole & $17(58.6)$ & $10(58.8)$ & $4(44.4)$ & $25(50.0)$ & $56(53.3)$ \\
Trimethroprim $(25 \mu \mathrm{g})$ & & & & & \\
Cloxacillin $(5 \mu \mathrm{g})$ & $26(89.7)$ & $17(100.0)$ & $7(77.8)$ & $38(76.0)$ & $88(83.8)$ \\
Tetracycline $(30 \mu \mathrm{g})$ & $8(27.6)$ & $5(29.4)$ & $1(11.1)$ & $17(34.0)$ & $31(29.5)$ \\
Ciprofloxacin $(5 \mu \mathrm{g})$ & $29(100.0)$ & $17(100.0)$ & $9(100.0)$ & $50(100.0)$ & $105(100.0)$ \\
Ofloxacin $(30 \mu \mathrm{g})$ & $0(0.0)$ & $0(0.0)$ & $0(0.0)$ & $1(2.0)$ & $1(0.9)$ \\
Amoxicillin $(25 \mu \mathrm{g})$ & $7(24.1)$ & $6(35.3)$ & $0(0.0)$ & $14(28.0)$ & $27(54.0)$ \\
\hline
\end{tabular}

Table 3. Antibiotic resistance patterns of the Listeria spp. isolated from different sources

\begin{tabular}{lllllll}
\hline Antibiotics & $\mathbf{F P I}$ & $\mathbf{F P P}$ & $\mathbf{P W I}$ & $\mathbf{P W P}$ & $\mathbf{F P W}$ & $\mathbf{P W}$ \\
& $\mathbf{n = 1 9}$ & $\mathbf{n = 2 0}$ & $\mathbf{n = 5 4}$ & $\mathbf{n = 1 2}$ & $\mathbf{n = 3 9}$ & $\mathbf{n = 6 6}$ \\
\hline Ampicillin $(10 \mu \mathrm{g})$ & $19(100.0)$ & $20(100.0)$ & $54(100.0)$ & $12(100.0)$ & $39(100.0)$ & $66(100.0)$ \\
Streptomycin $(10 \mu \mathrm{g})$ & $5(26.3)$ & $12(60.0)$ & $12(22.2)$ & $5(41.7)$ & $17(43.6)$ & $17(25.8)$ \\
Ceftriazone $(30 \mu \mathrm{g})$ & $19(100.0)$ & $20(100.0)$ & $51(94.4)$ & $12(100.0)$ & $39(100.0)$ & $63(95.5)$ \\
Chloramphenicol $(30 \mu \mathrm{g})$ & $0(0.0)$ & $0(0.0)$ & $4(7.4)$ & $11(91.7)$ & $0(0.0)$ & $15(22.7)$ \\
Sulfamethoxazole & $19(100.0)$ & $10(50.0)$ & $16(29.4)$ & $12(100.0)$ & $29(74.4)$ & $28(42.4)$ \\
Trimethroprim $(25 \mu \mathrm{g})$ & & & & & & \\
Cloxacillin $(5 \mu \mathrm{g})$ & $17(89.5)$ & $16(80.0)$ & $48(88.9)$ & $7(58.3)$ & $33(84.6)$ & $55(83.3)$ \\
Tetracycline $(30 \mu \mathrm{g})$ & $0(0.0)$ & $0(0.0)$ & $14(25.9)$ & $12(100.0)$ & $0(0.0)$ & $26(39.4)$ \\
Ciprofloxacin $(5 \mu \mathrm{g})$ & $19(100.0)$ & $20(100.0)$ & $54(100.0)$ & $12(100.0)$ & $39(100.0)$ & $66(100.0)$ \\
Ofloxacin $(30 \mu \mathrm{g})$ & $0(0.0)$ & $0(0.0)$ & $1(1.9)$ & $0(0.0)$ & $0(0.0)$ & $1(1.5)$ \\
Amoxicillin $(25 \mu \mathrm{g})$ & $10(50.0)$ & $10(50.0)$ & $8(14.8)$ & $0(0.0)$ & $20(51.3)$ & $8(12.1)$ \\
\hline \multicolumn{7}{c}{ Keys FPI: Fishpond water from the institution, FPP: Fish pond water from the private farm } \\
\multicolumn{7}{c}{ PWI: Poultry waste from the institution, PWP: Poultry waste from private farm } \\
FPW: Total from both fish pond water, PW: Total from both poultry waste
\end{tabular}


Table 4. Antibiotypes resistance pattern of Listeria species isolated from fish pond water samples. $n(\%)$

\begin{tabular}{|c|c|c|c|c|c|}
\hline Antibiotypes & $\begin{array}{l}\text { L. monocytogenes } \\
(\mathrm{n}=10)\end{array}$ & $\begin{array}{l}\text { L. ivanovii } \\
(\mathrm{n}=4)\end{array}$ & $\begin{array}{l}\text { L. innocua } \\
(\mathrm{n}=7)\end{array}$ & $\begin{array}{l}\text { Listeria spp. } \\
(\mathrm{n}=18)\end{array}$ & $\begin{array}{l}\text { Total } \\
(n=39\end{array}$ \\
\hline AMX-STR & $4(10.3)$ & $1(2.6)$ & $0(0.0)$ & $2(5.1)$ & $7(10.3)$ \\
\hline STR-SXT & $5(12.8)$ & $1(2.6)$ & $4(10.3)$ & $6(15.4)$ & $16(41.0)$ \\
\hline SXT-AMX & $4 \quad(10.3)$ & $3(7.7)$ & $0(0.0)$ & $7(10.3)$ & $14(35.9)$ \\
\hline AMP-CRO-CIP & $10(25.6)$ & $4(10.3)$ & $7(18.0)$ & $18(46.2)$ & $39(100)$ \\
\hline AML-SXT-STR & $4 \quad(10.3)$ & $1(2.6)$ & $0(0.0)$ & $2(5.1)$ & $7(10.3)$ \\
\hline SXT-CIP-CRO & $8 \quad(20.5)$ & $3(7.7)$ & $4(10.3)$ & $14(35.9)$ & $29(74.4)$ \\
\hline STR-CIP-CRO & $5 \quad(12.8)$ & $2(5.1)$ & $4(10.3)$ & $9(23.1)$ & $20(51.3)$ \\
\hline AMX-CIP-CRO & $4 \quad(10.3)$ & $3(7.7)$ & $0(0.0)$ & $8(20.5)$ & 15 \\
\hline SXT-CRO-CIP-AMX & $4 \quad(10.3)$ & $3(7.7)$ & $0(0.0)$ & $7(10.3)$ & $14(35.9)$ \\
\hline STR-AMX-CRO-CIP & $4 \quad(10.3)$ & $1(2.6)$ & $0(0.0)$ & $2(5.1)$ & $7(10.3)$ \\
\hline $\begin{array}{l}\text { SXT-STR-CIP-CRO- } \\
\text { AMP }\end{array}$ & $5(12.8)$ & $1(2.6)$ & $4(10.3)$ & $6(15.4)$ & $16(41.0)$ \\
\hline
\end{tabular}

Table 5. Antibiotypes resistance pattern of Listeria species isolated from poultry waste $\mathrm{n}(\%)$

\begin{tabular}{|c|c|c|c|c|c|}
\hline Antibiotypes & $\begin{array}{l}\text { L. monocytogenes } \\
\mathrm{n}=19\end{array}$ & $\begin{array}{l}\text { L. ivanovii } \\
\mathrm{n}=13\end{array}$ & $\begin{array}{l}\text { L. innocua } \\
\mathrm{n}=2\end{array}$ & $\begin{array}{l}\text { Listeria spp. } \\
\mathrm{n}=32\end{array}$ & $\begin{array}{l}\text { Total } \\
\mathrm{n}=66\end{array}$ \\
\hline CRO-CIP & $12(18.2)$ & $11(16.7)$ & $2(3.0)$ & $23(34.8)$ & $48(72.7)$ \\
\hline AMX-STR & $0(0.0)$ & $1(1.5)$ & $0(0.0)$ & $0(0.0)$ & $1(1.5)$ \\
\hline STR-SXT & $1(1.5)$ & $3(4.5)$ & $0(0.0)$ & $3(4.5)$ & $7(10.5)$ \\
\hline SXT-AMX & $0(0.0)$ & $1(1.5)$ & $2(3.0)$ & $0(0.0)$ & $3(4.5)$ \\
\hline AMP-CRO-CIP & $12(18.2)$ & $11(16.7)$ & $0(0.0)$ & $23(34.8)$ & $48(72.7)$ \\
\hline AML-SXT-STR & $0(0.0)$ & $1(1.5)$ & $0(0.0)$ & $0(0.0)$ & $1(1.5)$ \\
\hline SXT-CIP-CRO & $2(3.0)$ & $3(4.5)$ & $0(0.0)$ & $4(6.0)$ & $9(13.5)$ \\
\hline STR-CIP-CRO & $3(4.5)$ & $2(3.0)$ & $0(0.0)$ & $2(3.0)$ & 7 (10.5) \\
\hline AMX-CIP-CRO & $3(4.5)$ & $3(4.5)$ & $0(0.0)$ & $2(3.0)$ & $8(12.0)$ \\
\hline SXT-CRO-CIP-AMX & $0(0.0)$ & $1(1.5)$ & $0(0.0)$ & $0(0.0)$ & $1(1.5)$ \\
\hline STR-AMX-CRO-CIP & $0(0.0)$ & $1(1.5)$ & $0(0.0)$ & $0(0.0)$ & $1(1.5)$ \\
\hline SXT-STR-CIP-CRO & $1(1.5)$ & $2(3.0)$ & $0(0.0)$ & $1(1.5)$ & $4(6.0)$ \\
\hline TET-STR-CIP-CRO & $0(0.0)$ & $2(3.0)$ & $0(0.0)$ & $1(1.5)$ & $3(4.5)$ \\
\hline AMP-STR-SXT-C-CIP-TET & $3(4.5)$ & $0(0.0)$ & $0(0.0)$ & $4(6.0)$ & $7(10.5)$ \\
\hline AMP-TET-AMX-CIP-SXT-CHL & $0(0.0)$ & $0(0.0)$ & $0(0.0)$ & $1(1.5)$ & $1(1.5)$ \\
\hline
\end{tabular}

However, the results from this present study also revealed that the isolates from the fish pond water samples had a higher resistance $(74.4 \%)$ to sulfamethoxazole-trimethoprim than that of the poultry waste samples (42.4\%). This may be as a result of direct release of antibiotics into the fish pond. In addition, the total resistance to sulfamethoxazole-trimethoprim observed in both the institutional fish pond isolates and the private poultry farm isolates were much higher than $50 \%$ and $29.6 \%$ resistance which was observed in the isolates from the private fish pond water and institution poultry farm respectively. The reason for these differences may be as a result of misuse of this antibiotic on different farms sampled. This observation however is not in agreement with the resistance rate $(17.1 \%)$ reported from a study on frozen burger patties in
Malaysia [24]. Similarly, the resistance observed for L. monocytogenes (100\%), L. ivanovii $(100 \%)$, L. innocua $(100 \%)$ and the other Listeria spp. $(94 \%)$ to ceftriaxone in this study is a bit higher than the ones reported by Falodun et al. [10] where resistance to the same antibiotic was 90.9\% (L. monocytogenes), $82.4 \%$ (L. innocua), $73.3 \%$ (L. ivanovii) and $92.9 \%$ (other Listeria spp.). The observation from the result of the susceptibility test in this study showed that resistance of the isolates obtained from the fish pond water samples (100\%) and poultry waste samples $(95.5 \%)$ to ceftriaxone were high; the high resistant to this third generation antibiotic may be as a result of the development of natural resistance to the antibiotic. Moreover, resistance of the isolates to chloramphenicol $(0 \%)$ as observed in this study for both the institutional 
and private fish pond water samples, is in agreement with $(0 \%)$ resistance reported in Malaysia and Mangalore, India [23,25]. Whereas, the resistance $(91.7 \%)$ of the isolates from the poultry waste of the private farm to chloramphenicol is much higher than the $7.4 \%$ resistance obtained from the poultry waste of the institutional farm. This may be due to possible misuse of this antibiotic in the private poultry farm, while it may be that there is possibility of proper regulation of antibiotics usage in the Institutional farm.

\section{CONCLUSION}

In conclusion, the result of this study has further confirmed a high occurrence of Listeria species in environmental samples; $L$. monocytogenes is prevalent in the studied samples as well as a sizeable percentage of occurrences of $L$. ivanovii. The prevalence of these two species which have been implicated as human and animal pathogens could lead to the outbreak of listeriosis, which may results into death in poultry and fishes. The high antibiotic resistance exhibited by $L$. monocytogenes and $L$. ivanovii in these two environmental samples to ampicillin, ciprofloxacin and sulfamethoxazole-trimethoprim is suggestive of possibility of misuse of antibiotics either for therapeutic or other purposes in both fish pond and the poultry. This may lead to emergence, selection and dissemination of antibiotic resistant pathogenic Listeria species. Similarly, the high resistant exhibited by the Listeria spp. in this study to the third generation cephalosporins (ceftriaxone) which is the last resort for the treatment of listeriosis portend a difficult scenario for the treatment of listeriosis infection in the study area if there is outbreak of infection. Hence, adequate measures are to be put in place to regulate the use of antibiotics in animal husbandry and treatment of effluents and waste generated before they are discharged into the environment.

\section{COMPETING INTERESTS}

Authors have declared that no competing interests exist.

\section{REFERENCES}

1. Halter EL, Neuhaus K, Scherer S. Listeria weihenstephanensis spp. isolated from the water plant Lemna trisulca taken from a freshwater pond. Int J Syst Evo Microbiol. 2013;63:641-647.

2. Low JC, Donachie W. A review of Listeria monocytogenes and listeriosis. Vet $\mathrm{J}$. 1997;153:9-29.

3. Evans MR, Swaminathan B, Graves LM, Altermann E, Klaenhammer TR, Fink RC. Genetic markers unique to Listeria monocytogenes serotype $4 \mathrm{~b}$ differentiate epidemic clone II (hot dog outbreak strains) from other lineages. Appl Environ Microbiol. 2004;70:2383-90.

DOI: 10.1128/AEM.70.4.2383-2390

4. Barry AL, Thornsberry C. Susceptibility tests: Diffusion test procedures. In manual of clinical microbiology, edited by Lennette $\mathrm{EH}$, Balows A, Hausler WJ, Shadomy HJ. Washington DC: Am Soc Microbiol; 1997.

5. Ooi ST, Lorber B. Gastroenteritis due to Listeria monocytogenes. Clin infect Dis. 2005;40:1327-32.

6. Mafu A, Roy D, Goulet J, Magny P. Attachment of Listeria monocytogenes to stainless steel, glass, polypropylene and rubber surfaces after short contact times. J Food Prot. 1990;53:742-746.

7. Marshal BM, Levy SB. Food animals and antimicrobials impacts on human health. Clin Microbiol Rev. 2011;24:718-733.

8. Baquero $\mathrm{F}$, Martinez JL, Canton R. Antibiotics and resistance in water environments. Curr Opin Biotechnol. 2008;19(3):260-265.

9. Akpavie SO, Ikheloa JO. An outbreak of listeriosis in cattle in Nigeria. Revue d'Elevage et de Med Vet des Pays Trop. 1992;45:263-264.

10. Falodun OI, Rabiu AG, Fagade OE. Antibiotics susceptibility profile of Listeria species isolated from untreated abattoir wastewater in Akinyele, Ibadan, Nigeria and its implication on public health. British Biomed Res J. 2016;16(6):1-10.

DOI: $10.9734 / \mathrm{bmrj} / 2016 / 28066$

11. Atil E, Ertas HB, Ozbey G. Isolation and molecular characterization of Listeria spp. from animals, food and environmental samples. Vet Med. 2011;56(8):386-94.

12. Abhay VR, Swapnil PD, Krupali VP, Ajay $P$, Saroj B, Barbuddhe SB. Isolation and genotypic characterization of Listeria monocytogenes from pork and pork products. Int J Curr Microbiol Appl Sci. 2015;4(1):788-798.

13. Nwaiwu O. Presence of Listeria spp. in fish samples, fish products and sea products. Int Food Res J. 2015;22(2):455-464. 
14. Odjadjare EEO, Obi CL, Okoh Al. Municipal wastewater effluents as a source of listerial pathogens in the aquatic milieu of the Eastern Cape Province of South Africa: A concern of public health importance. Int J Environ Res Public Health. 2010;7:2376-239.

15. Moreno LZ, Paixão R, Gobbi DDS, Raimundo DC, Ferreira TP, Moreno AM, et al. Characterization of antibiotic resistance in Listeria spp. isolated from slaughterhouse environments, pork and human infections. J Infect Dev Countries. 2014;8(4):416-423.

16. Lloyd PC, Mabogunje AL, Awe B. The City of Ibadan. Cambridge University Press, Cambridge; 1967.

17. Akano SO, Moro DD, Agboola AM, Oluwadun A. Public health Implication of Listeria species and other bacteria isolates of abbatoir effluent in Lagos, Nigeria. Int Res J Microbiol. 2013;4(7):162-167.

18. Clinical and Laboratory Standards Institute (CLSI). Performance standards for antimicrobial disk susceptibility tests; $9^{\text {th }}$ ed.; Document M2-A9; Clinical and Laboratory Standards Institute (CLSI): Wayne, PA, USA; 2011.

19. Nwachukwu NC, Orji FA. Studies on the Isolation of Listeria monocytogenes from food, water, and animal droppings: Environmental Health Perspective, Environmental Health - Emerging Issues and Practice. 2012;978-953-307-854.
20. Arslan S, Ozdemir F. Prevalence and antimicrobial resistance of Listeria species in homemade white cheese. Food Control. 2008;19:360-363.

21. Issa ZM, Mustakim M, Mohamed SAS, Muda NM, Yen LH, Radu S. Antibiogram Profiles of Listeria monocytogenes isolated from foods. Int Conf Biotechnol Food Sci. 2011;7:133-137.

22. Nyenje ME, Ndip RN, Tanih NF, Green E. Current status of antibiograms of Listeria ivanovii and Enterobacter cloacae isolated from ready-to-eat foods in Alice, South Africa. Int J Environ Res Public Health. 2010;9:3101-3114.

23. Dhanashree B, Otta SK, Karunasagar I, Goebel W, Karunasagar I. Incidence of Listeria spp. in clinical and food samples in Mangalore, India. Food Microbiol. 2003;20: 447-453.

24. Wong WC, Pui CF, Tunung R, Ubong A, Noor HMS, Farinazleen MG. Antibiogram Pattern among Cultures of Listeria monocytogenes isolated from frozen burger patties in Malaysia. J Trop Agric Sci 2003;35:793-804.

25. Marian MN, Aminah SM, Zuraini MI, Son $R$, Maimunah M, Lee HY. "MPN-PCR detection and antimicrobial resistance of Listeria monocytogenes isolated from raw and ready-to-eat foods in Malaysia. Food Control. 2012;28:30914.

(0) 2017 Falodun and Amusan; This is an Open Access article distributed under the terms of the Creative Commons Attribution License (http://creativecommons.org/licenses/by/4.0), which permits unrestricted use, distribution, and reproduction in any medium, provided the original work is properly cited.

Peer-review history:

The peer review history for this paper can be accessed here: http://sciencedomain.org/review-history/19849 